\title{
Mobilidade cotidiana e as taxas de vitimização por acidentes de trânsito: o que é possível enxergar a partir dos dados censitários?*
}

\author{
Ana Carolina Soares Bertho ** \\ Tirza Aidar ${ }^{\star \star \star}$
}

\begin{abstract}
Este estudo avalia como a exposição ao risco de acidentes de trânsito pode ser potencializada pelas condições de mobilidade cotidiana dos indivíduos. Para isso, foram usados dados do Boletim de Ocorrência de acidentes fatais e não fatais de Campinas (SP) em 2009 e do Censo Demográfico de 2010. Os locais de residência das vítimas foram georreferenciados, permitindo o cálculo de taxas de vitimização por acidentes por área de ponderação que, por sua vez, foram relacionadas com informações socioeconômicas e de mobilidade. Embora as conclusões não possam ser inferidas em nível individual, observou-se que em áreas com maior proporção de pessoas com baixa renda há menores taxas de acidentes. Por outro lado, verificou-se correlação negativa entre áreas com maior proporção de pessoas com alta renda e taxas de vitimização de motociclistas. Os resultados mostram correlação positiva entre áreas com maior proporção de pessoas com renda domiciliar per capita de 1 a menos de 2 e de 2 a menos de 3 salários mínimos e taxas de vitimização por acidentes, bem como entre aquelas com maior proporção pessoas de 25 a 39 anos com ensino médio completo. Os resultados reforçam um possível uso desigual das vias públicas, onde quem pode se desloca com segurança e quem não pode se desloca pouco e, quando tem condições econômicas mínimas, o faz com pouca segurança.
\end{abstract}

Palavras-chave: Acidentes de trânsito. Mobilidade cotidiana. Desigualdades em saúde.

\footnotetext{
* A primeira autora agradece ao Conselho Nacional de Desenvolvimento Científico e Tecnológico (CNPq) pela bolsa de doutorado concedida, sendo este artigo parte dos resultados de sua tese de doutoramento.

** Escola Nacional de Ciências Estatísticas - Ence/IBGE, Rio de Janeiro-RJ, Brasil (carolina.bertho@ibge.gov.br).

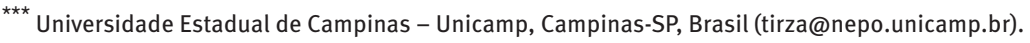




\section{Introdução}

De acordo com a Organização Mundial da Saúde (WHO, 2013), aproximadamente 1,24 milhão de pessoas morrem a cada ano vítimas de acidentes de trânsito no mundo. Cerca de $91 \%$ dessas mortes são de pessoas residentes em países com baixa renda, ainda que esses países tenham apenas metade da frota mundial (WHO, 2013). Ainda de acordo com a OMS, estima-se que outras 20 a 50 milhões de pessoas sofram acidentes não fatais, que muitas vezes resultam em incapacidade permanente. A preocupação crescente com a violência no trânsito levou à criação da Década de Ação pelo Trânsito Seguro 2011-2020, proposta pela Organização das Nações Unidas (WHO, 2011).

Dados do Sistema de Informações sobre Mortalidade (SIM) mostram que, em 2012, 44.812 pessoas morreram em decorrência de acidentes de transporte terrestre ${ }^{1}$ no Brasil (54,5\% de crescimento desde 2000), o que corresponde a 23,1 óbitos por 100 mil habitantes. A partir de dados de mortalidade de 2008, Chandran et al. (2013) mostraram que os homens tiveram uma redução de aproximadamente 0,8 ano de vida na expectativa de vida ao nascer devido às mortes por acidentes de trânsito, enquanto as mulheres tiveram uma redução de 0,2 ano.

Muitos fatores são apontados como causa do fenômeno: ausência de leis adequadas e/ou de fiscalização; falta de atenção ou de respeito para com os demais usuários da via pública (DA MATTA et al., 2010); uso de álcool por motoristas, bem como a adoção de comportamentos de risco no trânsito (ANDRADE et al., 2003); e condições de pavimento, fluxo de veículos e de pedestres, sinalização, velocidade e visibilidade (CARDOSO; GOLDNER, 2007). Sem negar a importância destes fatores, o objetivo do presente artigo é avaliar como a exposição ao risco de acidentes pode ser potencializada pelas condições de vida e de mobilidade cotidiana dos indivíduos. Entende-se por mobilidade cotidiana a soma dos deslocamentos individuais para ter acesso às oportunidades, sejam de estudos, trabalho, lazer, acesso a serviços ou convívio social (MIRALLES-GUASCH, 2002). Tal termo é usado para diferenciar esse tipo de deslocamento daquele que é conhecido como mobilidade residencial (mudança de domicílio).

\section{Uma breve revisão da literatura sobre acidentes de trânsito}

Nos países da Europa ocidental e na América do Norte, a preocupação com os acidentes de trânsito como uma das principais causas de lesões e morte surge já nos anos 1940 (JACOBS; SAYER, 1983). No Brasil, o tema começa a receber mais atenção de acadêmicos a

\footnotetext{
${ }^{1}$ Categorias V01 a V89 da CID-10. A definição de acidentes de transporte terrestre refere-se ao meio de transporte usado pela vítima e engloba todos os acidentes, exceto aqueles que envolveram meios marítimos, pluviais ou aéreos. Este termo difere de "acidentes de trânsito", usado no presente estudo, que corresponde a todos os acidentes de transporte terrestre, excluindo aqueles envolvendo meios de transporte ferroviário. A definição de acidentes de trânsito dada pelo Denatran é: "evento não intencional, envolvendo pelo menos um veículo, motorizado ou não, que circula por uma via para trânsito de veículos”.
} 
partir dos anos 1970, que destacam a incidência de acidentes de trânsito de veículo a motor entre os jovens e adultos jovens (LAURENTI et al., 1972). Como ressalta Mello-Jorge (1980), entre 1960 e 1975, a participação das mortes por causas violentas, também chamadas de causas externas, no total de óbitos aumentou de $6,54 \%$ para 8,10\%, no município de São Paulo. A autora observou ainda que os acidentes de trânsito, ${ }^{2}$ que em 1960 ocupavam a terceira posição entre os óbitos por causas violentas na capital paulista, passaram para a primeira colocação, em 1965, respondendo por 30,5\% do total desses óbitos. No início da década seguinte os acidentes de trânsito permaneceram na primeira posição, com aumento da participação para 43,7\% das mortes por causas violentas que ocorreram em São Paulo (MELLO-JORGE, 1980).

Scalassara et al. (1998), analisando os 65 óbitos por acidentes de trânsito que ocorreram no município de Maringá, no Paraná, em 1992, observaram que a maior parte das vítimas era do sexo masculino e tinha entre 20 e 49 anos. Quanto ao tipo de vítima, 19\% eram pedestres, $34 \%$ eram motociclistas (sendo $28 \%$ condutores e $6 \%$ passageiros) e $18 \%$ eram ciclistas. Estes percentuais mostram que, já na década de 1990, os motociclistas começaram a superar os pedestres em número absoluto de vítimas.

Usando dados de acidentes com vítimas fatais e não fatais também em Maringá, Soares (2003) traçou um perfil epidemiológico das vítimas e, por meio de uma análise de regressão logística, buscou fatores de risco para internação e óbito. A análise multivariada mostrou associação do risco de internação com as seguintes variáveis: vítimas pedestres, ciclistas e motociclistas; pessoas com mais de 50 anos; colisão com transporte pesado ou ônibus; acidentes ocorridos de madrugada e à tarde; e condutores residentes em Maringá. Já para o risco de óbito, as variáveis significativas para o ajuste do modelo foram: vítimas ciclistas, do sexo masculino e com mais de 50 anos; colisão com transporte pesado ou ônibus; condutores envolvidos em acidentes com três ou mais veículos; e acidentes com um veículo.

Bastos et al. (2005) também destacaram a participação das vítimas do sexo masculino e dos motociclistas em estudo sobre atendimento pré-hospitalar em Londrina, no Paraná. Ainda que o objetivo do trabalho tenha sido analisar as características dos acidentes e das vítimas, as autoras apontam para a importância das ações intersetoriais "que contemplem a prevenção dos acidentes de trânsito em todos seus aspectos, executadas de forma coordenada" (BASTOS et al., 2005, p.821).

Analisando as mortes por causas externas no município de Campinas-SP entre 1980 e 2000, Aidar (2003) observou que, no caso dos acidentes de transportes, ${ }^{3}$ os homens representaram 76,5\% das vítimas fatais em 1980 e 80,9\% em 2000. A partir do cálculo de Anos de Vida Perdidos, a autora constatou que, em 2000, homens e mulheres deixaram de ganhar aproximadamente 0,62 e 0,21 ano de expectativa de vida média, respectiva-

\footnotetext{
${ }^{2}$ A autora denomina mortes por "acidentes de trânsito" aquelas ocorridas por "acidentes de trânsito de veículos a motor", incluídas nas categorias E 810 a E 819 da 9ạ Revisão da Classificação Internacional de Doenças.

${ }^{3}$ A autora considerou mortes por acidentes de transporte aquelas classificadas de acordo com os códigos E800 a E848 da CID-9 em 1980 e 1991; e V00 a V99 da CID-10 para 2000.
} 
mente, em decorrência dos acidentes de transportes. Usando as áreas de residência das pessoas que morreram em decorrência de acidentes de transportes, Aidar (2003) indica que os subespaços ${ }^{4}$ com taxas mais elevadas em 2000 localizavam-se em áreas periféricas e eram cortados por rodovias de tráfego intenso. "São justamente nessas áreas que a população de baixo poder aquisitivo tem possibilidade de se estabelecer, muitas vezes de forma precária" (AIDAR, 2003, p. 78). A autora ressalta que, embora não fosse possível inferir sobre os locais de ocorrência dos eventos, assim como para os homicídios, os resultados apontaram para uma condição de vulnerabilidade maior da população residente nas periferias cortadas por rodovias e "nas áreas com maior proporção de população com baixa escolaridade e residente em favelas" (AIDAR, 2003, p.80). No que diz respeito à vulnerabilidade em relação ao trânsito urbano em particular, Aidar (2003) reforça a necessidade de aprofundamento e produção de informações que considerem também os locais de ocorrência e as características dos acidentes vis-à-vis a distribuição espacial e as condições de mobilidade cotidiana das populações em risco.

O georreferenciamento por setor censitário e a análise espacial também foram os recursos utilizados por Souza (2007) e Souza et al. (2008), que comparam locais de residência das vítimas fatais e de ocorrência dos acidentes no Rio de Janeiro, em 2003. Os autores utilizaram as Declarações de Óbito, para obter informações a respeito dos endereços de residência das vítimas e de ocorrência dos óbitos, e os registros de ocorrência dos acidentes da Polícia Civil, para o local de ocorrência dos acidentes. ${ }^{5} 0$ estudo indica que, como esperado, os locais de ocorrência dos óbitos se concentravam em áreas onde se localiza o maior centro de atendimento de emergência da cidade. Quanto aos locais de residência das vítimas, os autores identificaram pontos de "alto risco de morte por acidentes de trânsito", mas com diferenças importantes em comparação aos locais de ocorrência dos acidentes. Em uma sobreposição dos mapas de risco do local dos acidentes com as principais vias do município do Rio de Janeiro, observou-se que o maior risco de morte por colisões se concentrava nestas vias e os atropelamentos no centro da cidade. 0 mesmo resultado foi observado por Maia (2009) que, ao estudar a distribuição espacial dos acidentes de trânsito no município de São Paulo e a respectiva relação com a residência das vítimas, observou que grande parte das vítimas residia nas proximidades das áreas de concentração de ocorrências. 0 autor também identificou concentração de vítimas residindo em áreas mais distantes, padrão encontrado especialmente para os atropelamentos ocorridos no centro da cidade.

Se, por um lado, a identificação de áreas de risco do local de ocorrência dos eventos permite avaliação espacial de suma importância para a gestão do trânsito e segurança pública (SOUZA et al., 2008), por outro, a identificação dos grupos sociodemográficos

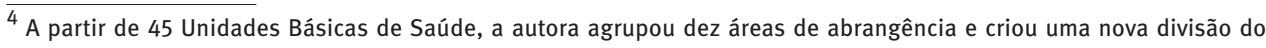
município, em 35 unidades de análise (AAs).

${ }^{5}$ Neste estudo foram georreferenciados, em nível de setor censitário, 85\% dos endereços de residência das vítimas, $83 \%$ dos endereços de ocorrência dos eventos e $95 \%$ dos endereços de ocorrência do óbito, sendo que a maioria desses últimos corresponde a unidades hospitalares (SOUZA, 2007).
} 
mais vulneráveis aos riscos oferecidos em determinadas áreas e circunstâncias adiciona informações fundamentais para ações de prevenção no âmbito da educação, saúde, transporte público, entre outras (BERTHO, 2010; MAIA; AIDAR, 2007).

Usando os locais de residência das vítimas como proxy das condições socioeconômicas das mesmas, Bertho (2010) analisou os acidentes de trânsito com vítimas fatais e não fatais ocorridos nas vias públicas municipais de Campinas em 2006. 0 estudo indica que, embora a população residente nas regiões centrais e norte do município apresente maior índice de mobilidade cotidiana, os locais de residência das vítimas pedestres de 0 a 14 anos e motociclistas de 15 a 24 anos estavam concentrados em áreas de vulnerabilidade social.

É preciso considerar que o índice de mobilidade - número de viagens realizadas em média por um indivíduo em um dia útil - varia de acordo com características socioeconômicas. A Pesquisa Origem e Destino (O/D) realizada em 2011 na Região Metropolitana de Campinas (STM, 2012) mostra que, quanto menor a renda, menor é o índice de mobilidade. Na Região Metropolitana, enquanto para a classe econômica "A" a média foi de 2,21 viagens/dia, entre as pessoas de classe "D” essa taxa caiu para 1,29 viagem/dia. Ou seja, quem tem maior renda não apenas possui maior disponibilidade de meios próprios de transporte motorizado, como também realiza maior número de viagens. A Pesquisa O/D também mostrou que o índice de imobilidade geral, ou seja, o percentual de população que não se deslocou para fora de casa nos dias de referência da pesquisa, foi de $29,3 \%$ (SMT, 2012). Quanto ao sexo, observou-se maior imobilidade para as mulheres $(34,5 \%$, contra $23,8 \%$ para os homens). Segundo grupos etários, este índice foi maior para idosos $(56,4 \%)$ e crianças (30,5\%). Desagregando os dados por nível de instrução, o maior índice de imobilidade foi registrado entre os analfabetos, reduzindo-se gradativamente com o aumento da escolaridade, exceto entre os que estudaram até a pré-escola. ${ }^{6}$ Diante dessas informações, cabe questionar: a incidência dos acidentes também poderia variar de acordo com as condições socioeconômicas nas áreas onde residem as vítimas?

\section{Fontes de dados e metodologia}

Desde os anos 1970, os Boletins de Ocorrência são usados para os estudos sobre acidentes de trânsito (LAURENTI et al., 1972). Entre as vantagens do uso dessa fonte de informação se destaca a possibilidade de coleta de dados como local e tipo do acidente,

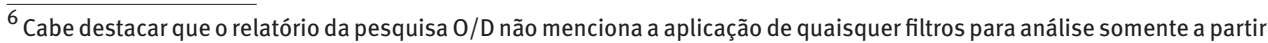
de determinada idade. Assim, entre os analfabetos estão incluídas as crianças que ainda não frequentam a escola, o que justifica a alta imobilidade nesse grupo. 0 mesmo pode ser dito a respeito dos que têm grau de instrução "pré-escolar". Se uma criança está em fase pré-escolar, é porque ela vai à escola (portanto, realiza deslocamentos). Caso contrário, ela seria analfabeta. Isso justificaria a baixa imobilidade das pessoas com esse grau de instrução. Para eliminar a dúvida a respeito dos possíveis efeitos de composição etária no resultado apresentado no relatório da Secretaria de Transportes Metropolitanos, realizou-se uma nova tabulação destes dados, selecionando-se apenas as pessoas com mais de 25 anos de idade. Os resultados obtidos mostram grande semelhança com os do relatório, corroborando a afirmação de que quanto maior a escolaridade, menor é a taxa de imobilidade dos indivíduos.
} 
tipo do veículo envolvido, número de vítimas e características das mesmas e residência dos envolvidos.

As informações sobre acidentes foram obtidas no banco de dados produzido e organizado pela Empresa Municipal de Desenvolvimento de Campinas/Secretaria Municipal de Transportes (Emdec/Setransp), a partir de cópias de Boletins de Ocorrência de acidentes de trânsito que ocorreram em 2009 nas vias públicas municipais. Foram selecionados os acidentes com vítimas fatais e não fatais - ou seja, pessoas que se feriram em acidentes, mas não morreram em decorrência deles.

Além das informações dos Boletins de Ocorrência, a Emdec/Setransp complementa as informações sobre vítimas fatais que não faleceram no local do acidente, a partir de documentos do Instituto Médico Legal (IML), das 13 Delegacias de Polícia Civil da cidade, dos Serviços Técnicos Gerais (Setec) e da Polícia Militar. Após o recolhimento dos dados nesses órgãos, são excluídas as vítimas fatais que sofreram acidentes em outros municípios e faleceram em Campinas e incluídas aquelas que faleceram em outros municípios, mas sofreram o acidente em Campinas. Esse procedimento garante maior cobertura dos óbitos (no caso de acidentes fatais) (EMDEC, 2010).

A partir do banco de dados da Emdec, foi feita a transcrição ${ }^{7}$ dos endereços de residência de 5.168 vítimas fatais e não fatais contidos em 4.187 Boletins de Ocorrência (BO). 0 georreferenciamento dos locais de residência das vítimas foi feito sobre a base de logradouros produzida pela Emdec (2014). Utilizou-se o software livre TerraView 4.2.0.

Neste artigo, não foi feita a análise do georreferenciamento dos locais de ocorrência dos acidentes, por não estar incluída em seu objetivo principal. Porém, cabe ressaltar que estudo anterior mostrou que a maioria dos acidentes ocorreu no centro da cidade, bem como em grandes avenidas, locais em que o fluxo de pessoas e veículos é intenso (BERTHO, 2014). Esse resultado também foi encontrado por Souza (2007) que, a partir de dados de acidentes de trânsito com vítimas fatais no Rio de Janeiro em 2003, observou que grande parte dos atropelamentos ocorreu no centro do município, o que poderia ser justificado pelo fluxo intenso de pedestres. Por outro lado, a autora constatou que os outros tipos de acidentes se concentraram em uma área por onde passa uma das vias mais importantes da cidade. A informação sobre o local de ocorrência dos acidentes é relevante e amplamente utilizada pela Secretaria Municipal de Transportes de Campinas para adoção de medidas preventivas, tais como melhoria da sinalização, aumento da fiscalização para coibir infrações que coloquem em risco a vida das pessoas, instalação de radares para controle da velocidade, entre outras. Entretanto, o presente artigo focaliza apenas os locais de residência das vítimas fatais e não fatais, pois busca esclarecimentos a respeito das condições socioeconômicas e de mobilidade das pessoas que sofreram acidentes e usa a área de residência como proxy das condições socioeconômicas das vítimas.

\footnotetext{
${ }^{7}$ Uma vez que a Emdec não utiliza a informação de endereço de residência das vítimas e as cópias dos Boletins de Ocorrência não podem ser retiradas da Emdec e nem replicadas, a autora passou aproximadamente quatro meses trabalhando dentro da empresa para transcrever tais informações para o banco de dados já existente.
} 
Após o georreferenciamento dos locais de residências das vítimas, foi feita a leitura desses endereços para cada área de ponderação (AP) do Censo Demográfico 2010, que passou a ser a unidade de análise. A área de ponderação é a menor unidade geográfica de desagregação para os dados provenientes da amostra do Censo, sendo composta por um conjunto de setores censitários contíguos, com tamanho mínimo definido em 400 domicílios ocupados na amostra (IBGE, 2013). Em 2010, o município de Campinas foi dividido em 36 APs. Usando como denominador a população de cada AP, ${ }^{8}$ foram então calculadas taxas de vitimização. Além da taxa de vitimização total (total de vítimas que residiam na AP por 100 mil habitantes da mesma AP), foram calculadas taxas de vitimização de pedestres (número de vítimas pedestres por 100 mil habitantes) e de motociclistas, sendo que neste último caso foi considerado apenas o número de motociclistas (condutores ou garupas) de 15 a 34 anos que sofreram acidentes, dividido pela população de 15 a 34 anos.

Do Censo 2010 foram selecionadas variáveis de renda domiciliar per capita em salários mínimos, nível de instrução e duas variáveis que se relacionam às condições de mobilidade cotidiana: tempo de deslocamento entre a residência e o local de trabalho; e existência de carro e/ou motocicleta no domicílio. Algumas considerações devem ser feitas a respeito destas variáveis. ${ }^{9}$

Para identificação das características econômicas de cada AP, foi selecionada a variável rendimento mensal domiciliar per capita em número de salários mínimos em julho de 2010 , identificada pelo código V6532 nos microdados do Censo de 2010. Devido à assimetria da distribuição da variável renda, à maior dispersão das taxas de vitimização entre as AP de mais baixa renda média e à indicação de relação não linear das taxas de vitimização, em acidentes de moto em especial, com a média do rendimento domiciliar per capita, optou-se pela categorização desta em quatro classes de rendimento: menos de um salário mínimo; de 1 a menos de 2 salários mínimos; de 2 a menos de 3 salários mínimos; e a partir de três salários mínimos. ${ }^{10}$ Foram consideradas as proporções de pessoas residentes em domicílios com determinada faixa de renda, por AP. Elaboraram-se análises descritivas e diagramas de dispersão entre as taxas de vitimização e as características socioeconômicas e de mobilidade da população residente nas APs (tabela e gráficos no Apêndice).

Para análise da escolaridade da população residente, foi usada a variável nível de instrução (V6400), construída pelo IBGE a partir das informações sobre série e grau de instrução para as pessoas que frequentavam escola e maior grau concluído para aquelas

\footnotetext{
8 Embora os acidentes tenham ocorrido em 2009 e os dados do Censo Demográficos refiram-se a 2010, pela proximidade temporal considerou-se que não haveria prejuízos significativos à análise ao se fazer o cálculo de taxas usando os dados censitários.

${ }^{9}$ As definições das variáveis foram obtidas a partir da metodologia do Censo Demográfico 2010 (IBGE, 2013).

10 Com o objetivo de estudar a importância dos extremos em termos de rendimento domiciliar per capita, inicialmente foram definidas oito categorias: de 0 a menos de $1 / 2$ salário mínimo; de $1 / 2$ a menos de 1 ; de 1 a menos de 2 ; de 2 a menos de 3; de 3 a menos de 5; de 5 a menos de 10; de 10 a menos de 20; e a partir de 20. Quando comparados os coeficientes de correlação entre a proporção de domicílios em cada uma destas faixas de rendimento e as taxas de vitimização por acidentes de trânsito, os resultados não indicaram diferenciação entre as duas primeiras faixas, tampouco entre as quatro últimas. Por esta razão, para o artigo estão apresentadas apenas as quatro faixas de rendimento.
} 
que não frequentavam (IBGE, 2013). A variável coletada em nível individual é categórica e a classificação é a seguinte: sem instrução e fundamental incompleto; fundamental completo e médio incompleto; médio completo e superior incompleto; superior completo e não determinado. Para eliminar os efeitos de composição etária da população da AP, foi feito um recorte que considera apenas a escolaridade das pessoas de 25 a 39 anos (cerca de $26 \%$ da população), pois é esperado que uma AP com alto percentual de pessoas idosas, ou de crianças em idade escolar, tenha uma escolaridade média mais baixa - sem que isso necessariamente signifique piores condições de escolarização e sociais para a população em questão. Por este motivo, optou-se pelo uso do nível de instrução dos adultos jovens como uma proxy da escolaridade da área, em vez da padronização, que, embora permitisse a comparação entre as APs com distintas estruturas etárias, dificultaria a interpretação dos resultados. Assim, o indicador usado foi a proporção de pessoas de 25 a 39 anos em cada faixa de escolaridade mencionada anteriormente.

Para análise das condições de mobilidade dos indivíduos residentes nas APs do município, foram selecionadas três perguntas do Censo 2010: V0662 - "Qual é o tempo habitual gasto de deslocamento de sua casa até o trabalho?”; V0221 - "Neste domicílio existe motocicleta para uso particular?"; e V0222 - “Neste domicílio existe automóvel para uso particular?” A primeira pergunta é respondida apenas pelas pessoas que trabalham e se deslocam diariamente por este motivo. Esta variável é categórica ordinal e foi mantida tal como está no Censo, sendo que as duas últimas categorias foram somadas: até 5 minutos; de 6 a 30 minutos; mais de 30 a 60 minutos; e mais de 60 minutos. ${ }^{11}$ Porém, para o nível de análise do trabalho, também neste caso, foi analisada a proporção de pessoas da AP por faixas de tempo de deslocamento casa-trabalho. Embora os acidentes não necessariamente ocorram no trajeto casa-trabalho, parte-se do pressuposto de que os obstáculos ou facilidades encontrados na realização deste percurso cotidiano possam se reproduzir em outras situações, como nos deslocamentos para estudos, acesso a serviços e lazer. A segunda e a terceira variáveis escolhidas foram agrupadas em uma nova variável categórica nominal, chamada "existência de meios próprios de transporte motorizado", composta pelas categorias: nenhum (quando o domicílio não tem moto nem automóvel); somente moto; somente automóvel; e moto e automóvel. Mesmo que a existência de um meio de transporte motorizado no domicílio não comprove a utilização do mesmo para os deslocamentos diários, tampouco informe sobre quais indivíduos do domicílio utilizam o(s) veículo(s) declarado(s), trata-se de mais um indicador de condições socioeconômicas e de mobilidade. Uma vez que a unidade espacial de análise é a AP, as respostas possíveis compreendem, por exemplo, a "proporção de indivíduos residentes na AP que moram em domicílios que não têm automóvel ou motocicleta”, a "proporção de indivíduos residentes na AP que moram em domicílios que têm somente automóvel”, e assim por diante. Embora as informações censitárias não tenham sido levantadas para mensurar, ou tratar da mobi-

\footnotetext{
${ }^{11}$ No Censo, existem as categorias “mais de 60 a 120 minutos" e "mais de 120 minutos", mas para o artigo essas categorias foram agregadas.
} 
lidade cotidiana, considerou-se sua importância para a presente pesquisa como forma de explorar fontes alternativas para estudos em áreas urbanas onde não existem fontes de informações específicas como a Pesquisa Origem e Destino.

Foram feitas análises de correlação de Pearson com as informações por AP: taxas de vitimização (total, pedestres e motociclistas), condições socioeconômicas (renda domiciliar per capita e escolaridade) e condições de mobilidade (posse de meios próprios de transporte motorizado e tempos médios de deslocamento casa-trabalho). Os resultados são apresentados a seguir.

\section{Resultados e discussão}

Das 5.168 pessoas que sofreram acidentes nas vias públicas municipais de Campinas, ${ }^{12}$ em 2009, 4.419 moravam no município. Todas as análises apresentadas a seguir referem-se a este total de vítimas residentes em Campinas. Dessas, 70,7\% (3.123 pessoas) eram homens e $29,1 \%$ (1.287) eram mulheres. 0 percentual de vítimas cujo sexo não foi especificado no Boletim de Ocorrência corresponde a 0,2\% do total (nove pessoas). Quanto aos grupos etários, destacam-se as vítimas com idade entre 20 e 24 anos, com participação de $25,2 \%$, seguidas pelas pessoas de 25 a 29 anos, que respondem por $16,2 \%$ do total. Quando se avalia a participação por sexo, em cada grupo etário, observa-se que em todas as idades o número homens é superior ao de mulheres.

Das 4.419 vítimas que residiam em Campinas, foi possível fazer o georreferenciamento dos endereços de residência de $3.652\left(82,6 \%{ }^{13}\right)$. Este total foi usado para o cálculo das taxas, que têm como denominador a população residente em cada AP.

A análise das vítimas por tipo de veículo que ocupavam no momento do acidente mostra que a maior parte era composta por motociclistas (aproximadamente $50 \%$ do total), seguida pelos ocupantes dos demais veículos (30\%), pedestres (15\%) e ciclistas (4\%). Dada a importância de se estudar separadamente as vítimas pedestres e os motociclistas, chamados de usuários vulneráveis do sistema viário ${ }^{14}$ (GLOBAL ROAD SAFETY PARTNERSHIP, 2008), optou-se por realizar a análise dessa forma. Por este motivo, as taxas são calculadas para o total de vítimas, ${ }^{15}$ para os pedestres e para os motociclistas de 15 a 34 anos, sendo que neste último caso o denominador é dado pela população deste mesmo grupo etário.

\footnotetext{
$\overline{12}$ A expressão "total de vítimas" faz referência a esse universo, composto por vítimas fatais e não fatais de acidentes de trânsito ocorridos em vias públicas municipais de Campinas em 2009.

${ }^{13} 0$ missing do georreferenciamento dos locais de residência deve-se não apenas à incompletude no preenchimento dos dados, mas principalmente à dificuldade de localização de logradouros cujos nomes são designados por numerais (p. ex.: R. Dezoito). Das 767 vítimas cujos locais de residência não foram localizados, quase metade dos endereços tinha o nome do logradouro designado por numerais.

${ }^{14}$ Nessa definição também estão incluídos os ciclistas, porém, por totalizarem apenas 172 vítimas (3,9\% do total), optou-se por não analisá-los separadamente, como foi feito com pedestres e motociclistas.

${ }^{15}$ A classificação feita pela Emdec permite identificar condutor de moto, condutor de bicicleta, condutor de demais veículos, passageiro de moto, passageiro de bicicleta, passageiro dos demais veículos, pedestres e vítimas com informação não especificada (esta última categoria inclui menos de $1 \%$ das vítimas).
} 
A Tabela 1 mostra resultados já esperados: associação positiva entre a proporção de pessoas da AP com renda domiciliar per capita de menos de um salário mínimo e de 1 a menos de 2 salários mínimos e a proporção de pessoas da AP vivendo em domicílios com nenhum meio de transporte ou somente moto. Também observou-se correlação negativa entre as proporções de pessoas com renda domiciliar per capita de menos de dois salários mínimos e de pessoas vivendo em domicílios com carro.

TABELA 1

Coeficiente de correlação de Pearson entre proporção de residentes em domicílios com meios próprios de transporte para área de ponderação e proporção de população, segundo faixas de renda domiciliar per capita para área de ponderação

Município de Campinas - 2010

\begin{tabular}{lcccc}
\hline \multirow{2}{*}{$\begin{array}{c}\text { Faixas de renda } \\
\text { (em salários mínimos) }\end{array}$} & \multicolumn{2}{c}{ Residentes em domicílios com meios próprios de transporte } \\
\cline { 2 - 5 } Menos de 1 SM & Nenhum & Moto & Carro & Ambos \\
De 1 a menos de 2 SM & $0,828^{\star \star}$ & $0,829^{\star \star}$ & $-0,868^{\star \star}$ & $-0,437^{\star \star}$ \\
De 2 a menos de 3 SM & $-0,507^{\star \star}$ & $0,474^{\star \star}$ & $-0,545^{\star \star}$ & 0,02 \\
A partir de 3 SM & $-0,770^{\star *}$ & $-0,681^{\star \star}$ & $0,553^{\star \star}$ & 0,317 \\
\hline
\end{tabular}

Fonte: IBGE. Censo Demográfico 2010.

* Correlações significativas ao nível de 5\%; ${ }^{* *}$ correlações significativas ao nível de $1 \%$.

De maneira complementar, à medida que as faixas de renda aumentam, os coeficientes mostram relações inversas: a partir de 2 a menos de 3 salários mínimos de renda domiciliar per capita, a proporção de pessoas por AP mostrou correlação negativa com a proporção de residentes em domicílios sem meios próprios de transporte ou somente com moto e correlação positiva com a proporção de pessoas residentes em domicílios com carro. Os diagramas de dispersão (Gráficos 1 e 2) possibilitam outra visualização dos resultados que estão de acordo com o esperado: quanto maior o rendimento médio da AP, maior é a proporção de pessoas com possibilidade e mobilidade cotidiana individual, ou autônoma, de carro e/ou motocicleta.

A Tabela 2 mostra os coeficientes de correlação de Pearson entre as taxas de vitimização (total - incluindo acidentes automotor, pedestres e motociclistas, por 100 mil habitantes) ${ }^{16}$ e a renda domiciliar per capita e escolaridade dos adultos jovens de 25 a 39 anos. Destaca-se a correlação positiva entre taxas de vitimização (total e de motociclistas) e a proporção de pessoas com renda domiciliar per capita de 1 a menos de 2 salários mínimos, bem como a correlação positiva entre taxa de vitimização total e proporção de pessoas com renda domiciliar per capita de 2 a menos de 3 salários mínimos. Quanto à relação entre escolaridade e taxas de vitimização, sobressai a correlação positiva com a proporção de pessoas com ensino médio.

\footnotetext{
$\overline{16}$ Das 4.419 vítimas, apenas 260 (5,9\%) sofreram acidentes envolvendo ônibus, o que justifica essas vítimas não terem sido tratadas separadamente. Entre estas estão aquelas que foram atropeladas por ônibus, analisadas dentro no conjunto dos "pedestres". Cabe destacar que, de acordo com a Pesquisa Origem e Destino (O/D) realizada em 2011 na Região Metropolitana de Campinas (RMC), do total de viagens com origem dentro do município de Campinas, 34,4\% utilizaram meios de transporte coletivo (STM, 2012), o que mostra que, considerando o uso dos meios de transporte, o número de vítimas é relativamente baixo.
} 


\section{GRÁFICO 1}

Percentual de população residindo em domicílios com ou sem carro e motocicleta por percentual de população com rendimento domiciliar per capita de menos de um salário mínimo para áreas de ponderação Município de Campinas - 2010

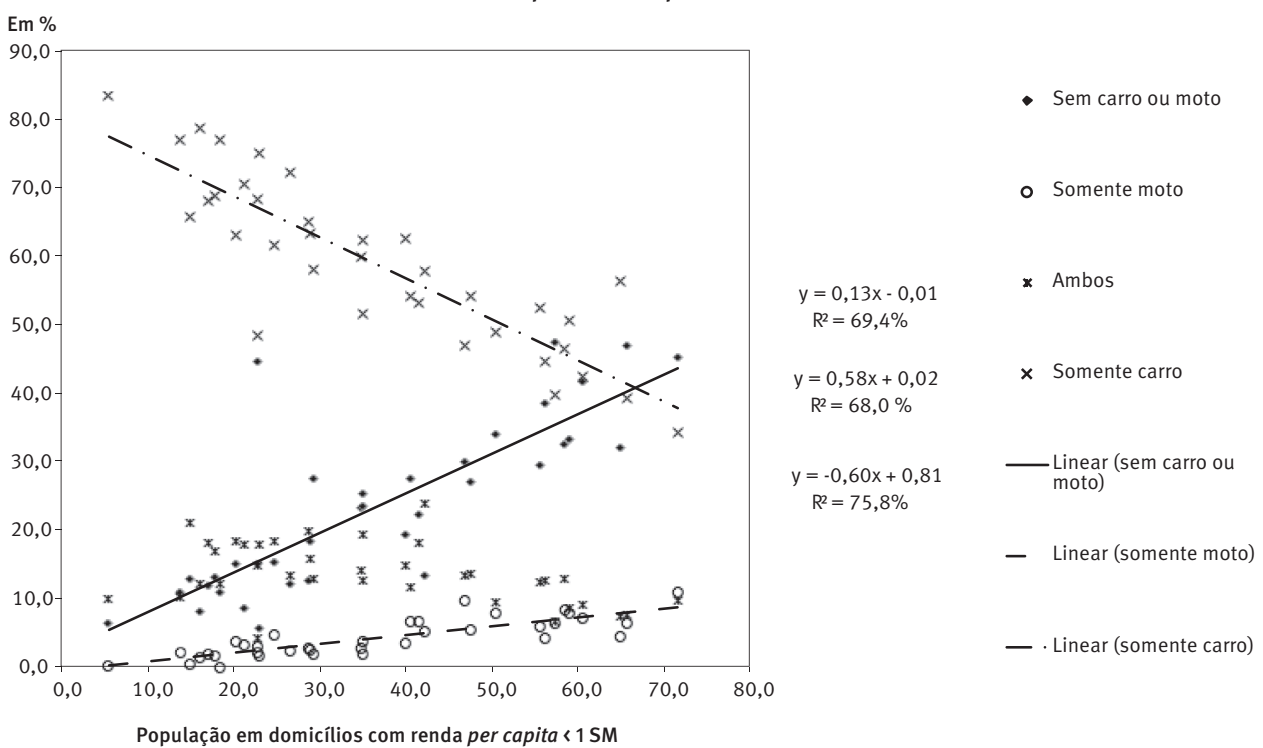

Fonte: IBGE. Censo Demográfico 2010.

\section{GRÁFICO 2}

Percentual de população residindo em domicílios com ou sem carro e motocicleta por percentual de população com rendimento domiciliar maior ou igual a três salários mínimos para áreas de ponderação Município de Campinas - 2010

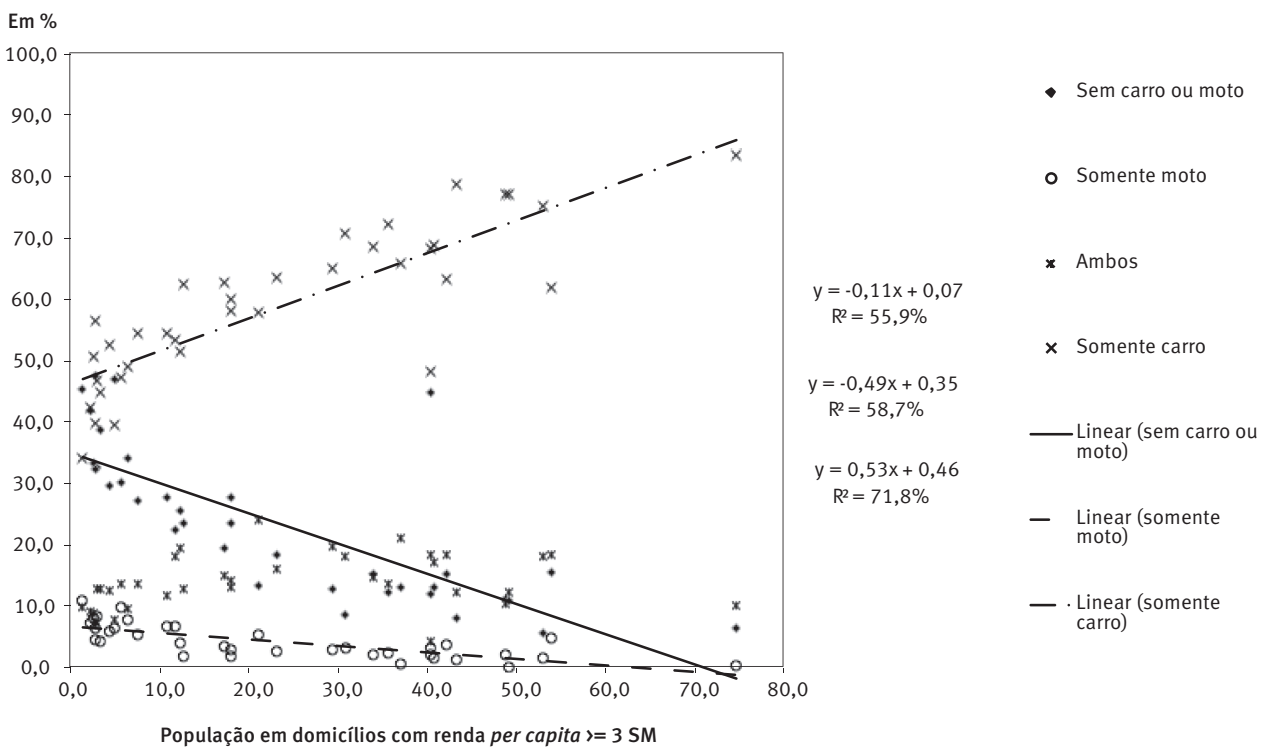

Fonte: IBGE. Censo Demográfico 2010. 
TABELA 2

Coeficiente de correlação de Pearson entre taxas de vitimização devido a acidentes de trânsito, proporção de pessoas por faixa de renda domiciliar per capita e proporção de adultos de 25 a 39 anos por escolaridade para áreas de ponderação Município de Campinas - 2009

\begin{tabular}{|c|c|c|c|}
\hline \multirow{2}{*}{ Indicadores } & \multicolumn{3}{|c|}{ Taxas de vitimização por 100 mil habitantes } \\
\hline & Total & Pedestres & Motociclistas (1) \\
\hline \multicolumn{4}{|c|}{$\begin{array}{l}\text { Proporção de pessoas por AP por faixas de renda } \\
\text { domiciliar per capita (em salários mínimos) }\end{array}$} \\
\hline Menos de 1 SM & $-0,07$ & 0,12 & 0,04 \\
\hline De 1 a menos de 2 SM & $0,342^{\star}$ & 0,21 & $0,471^{\star \star}$ \\
\hline De 2 a menos de $3 \mathrm{SM}$ & $0,375^{\star}$ & 0,16 & 0,32 \\
\hline A partir de 3 SM & $-0,16$ & $-0,23$ & $-0,30$ \\
\hline \multicolumn{4}{|c|}{$\begin{array}{l}\text { Proporção de pessoas de } 25 \text { a } 39 \text { anos por AP } \\
\text { por escolaridade }\end{array}$} \\
\hline Nenhuma ou fundamental incompleto & $-0,25$ & $-0,13$ & $-0,10$ \\
\hline Fundamental completo & 0,13 & 0,20 & 0,28 \\
\hline Médio completo & $0,526^{\star *}$ & $0,445^{\star \star}$ & $0,570^{\star *}$ \\
\hline Superior completo & $-0,11$ & $-0,18$ & $-0,26$ \\
\hline
\end{tabular}

Fonte: IBGE. Censo Demográfico 2010. Emdec/Setransp (2010).

(1) Vítimas motociclistas de 15 a 34 anos divididas pela população de 15 a 34 anos.

* Correlações significativas ao nível de 5\%; ** correlações significativas ao nível de $1 \%$.

A Tabela 3 relaciona as taxas de vitimização com indicadores de mobilidade. Esta análise apresentou apenas dois resultados com significância. 0 primeiro indica associação negativa entre a proporção de pessoas residentes em domicílio com carro e moto e a taxa de vitimização de pedestres. 0 segundo resultado significativo encontrado foi a correlação negativa entre proporção de pessoas que levam até 5 minutos se deslocando de casa para o trabalho e a taxa de vitimização de motociclistas.

TABELA 3

Coeficiente de correlação de Pearson entre taxas de vitimização devido a acidentes de trânsito e características da mobilidade para áreas de ponderação Município de Campinas - 2009

\begin{tabular}{lccc}
\hline \multicolumn{1}{c}{ Indicadores } & \multicolumn{2}{c}{ Taxas de vitimização por 100 mil habitantes } \\
\cline { 2 - 3 } & Total & Pedestres & Motociclistas (1) \\
\hline Proporção de pessoas por AP residentes em & & & \\
domicílios com carro ou moto & & & $-0,008$ \\
$\quad$ Sem carro nem moto & $-0,088$ & 0,237 & $-0,020$ \\
Com moto & $-0,149$ & 0,012 & $-0,024$ \\
Com carro & 0,100 & $-0,098$ & 0,101 \\
Com carro e moto & 0,065 & $-0,398^{\star}$ & \\
\hline Proporção de pessoas por AP por tempo de & & & $-0,339^{\star}$ \\
deslocamento casa-trabalho & & & $-0,283$ \\
Até 5 minutos & $-0,215$ & $-0,200$ & 0,269 \\
De 6 a 30 minutos & $-0,159$ & $-0,280$ & 0,288 \\
Mais de 30 a 60 minutos & 0,114 & 0,194 & 0,318 \\
Mais de 60 minutos & 0,211 & & \\
\hline
\end{tabular}

Fonte: IBGE. Censo Demográfico 2010. Emdec/Setransp (2010).

(1) Vítimas motociclistas de 15 a 34 anos divididas pela população de 15 a 34 anos.

* Correlações significativas ao nível de 5\%; ** correlações significativas ao nível de $1 \%$. 


\section{Considerações finais}

Os impactos para a saúde da população em função dos acidentes de trânsito são motivo de preocupação em todo o mundo, pois a cada ano aproximadamente 1,2 milhão de pessoas morrem por esta causa (WHO, 2013). Em 2012, o Brasil registrou quase 45 mil óbitos por acidentes de trânsito. A importância de se estudar o fenômeno está não apenas nos anos potenciais de vida perdidos por esta causa, mas também por ser reflexo de décadas de contínuo crescimento urbano no país e da respectiva dinâmica econômica e populacional dentro e entre as maiores aglomerações urbanas, que acontecem, em grande medida, de forma desordenada, sem o devido planejamento e ações eficazes para atenderem às novas demandas para a mobilidade cotidiana e transporte intra e intermunicipal.

Foi com tal preocupação que se produziu esse artigo, buscando acrescentar conhecimento ao debate existente nas, e entre, diversas áreas que estudam o tema. A metodologia e as fontes usadas nas pesquisas conduzidas por demógrafos não são exclusivas deste campo do conhecimento, mas as particularidades emergem na formulação das hipóteses e na interpretação das informações. No caso do presente estudo, procurou-se avaliar como a exposição ao risco de acidentes pode ser potencializada pelas condições de mobilidade da população. Avalia-se que, mesmo com diversas limitações, o Censo Demográfico 2010 revelou potencialidades para os estudos sobre mobilidade e exposição aos riscos no trânsito urbano, a partir do número e tempo de deslocamentos e da existência ou não de meios próprios de transporte. Este estudo teve como desafio trabalhar com informações coletadas em nível individual tanto das vítimas de acidentes quanto das condições socioeconômicas e de mobilidade da população, mas todas estimadas em um âmbito mais agregado, que é a área de ponderação. Como a análise só foi possível graças à agregação dos dados, perde-se o detalhamento e não se pode garantir que as vítimas foram aquelas do grupo mais ou menos abastado. Por outro lado, os resultados observados para as taxas específicas por tipo e número de deslocamentos reforçam o entendimento de que o espaço de residência reflete também os constrangimentos quanto à realização da mobilidade cotidiana de forma segura.

As análises de correlação entre renda domiciliar per capita e a existência de meios próprios de transporte no domicílio mostraram resultados que poderiam ser esperados: associação positiva entre baixa renda e a proporção de pessoas da AP vivendo em domicílios com nenhum meio de transporte ou somente moto. Por outro lado, a partir de 2 a menos de 3 salários mínimos de renda domiciliar per capita há correlação positiva e significativa com a proporção de pessoas residentes em domicílios com carro ou com carro e moto.

No caso da taxa de vitimização de motociclistas por 100 mil pessoas, observou-se correlação positiva com a proporção de pessoas com renda domiciliar per capita de 1 a menos de 2 salários mínimos. Quanto à relação entre escolaridade e taxas de vitimização total, destacou-se a correlação positiva com a proporção de adultos de 25 a 39 anos com ensino médio. 
Embora as conclusões não possam ser inferidas para o nível individual, observa-se que, em áreas com maiores percentuais de pessoas com baixa renda, há menor posse de meios próprios de transporte e menores taxas de acidentes (BERTHO, 2014). A condição que "propicia” a vitimização é intermediária. Talvez porque as pessoas residentes em áreas intermediárias tenham um pouco mais de condições de escolha e, para alcançar maior controle sobre o próprio tempo, flexibilidade e possibilidade de acesso a bens e serviços, incluindo trabalho, decidem pela utilização de motocicleta, apesar dos riscos que este meio de transporte oferece.

A pesquisa dá indícios de que a imobilidade, maior entre as pessoas menos escolarizadas e com menor renda (STM, 2012), reduz o risco de morte por acidentes por diminuir a exposição das vítimas aos perigos do trânsito, ao mesmo tempo em que a melhor condição das pessoas que residem em área de maior riqueza permite que os deslocamentos sejam realizados com maior segurança - em última instância, porque provavelmente aqueles com maior renda utilizam mais carros. Mas nenhum dos dois extremos mostra um "ideal” de mobilidade ou de segurança no trânsito. Eles apenas reforçam o uso desigual das vias públicas, onde quem pode se desloca muitas vezes e, provavelmente, com maior segurança e quem não pode se desloca pouco e, quando tem condições econômicas mínimas, o faz com pouca segurança.

Entretanto, deve ser ressaltado que, embora tais resultados sejam coerentes com estudos anteriores, o baixo risco de vitimização da população residente nas áreas urbanas com os piores indicadores socioeconômicos pode ser resultado da seletividade do sucesso da localização dos endereços das vítimas. Em outras palavras, caso os endereços não identificados $(17,4 \%)$ sejam de vítimas residentes nessas áreas com piores indicadores, a relação será mais linear, isto é, quanto mais precária a situação socioeconômica e de mobilidade (pouca e/ou insegura), maior é o risco de vitimização em acidentes de trânsito.

Os resultados mostram que, apesar das dificuldades metodológicas, os Boletins de Ocorrências são fontes ricas quando se pretende saber, além da idade, sexo, tipo de veículo envolvido e outras informações referentes à ocorrência, os endereços de residência das vítimas. Embora os Boletins de Ocorrência não permitam identificar as características socioeconômicas individuais, por meio do georreferenciamento dos endereços das vítimas é possível traçar um perfil das áreas onde residiam essas vítimas, servindo como uma aproximação das suas condições socioeconômicas. A pesquisa também avança ao buscar no Censo Demográfico 2010 informações a respeito das condições socioeconômicas e de mobilidade de áreas menores que compõem o município. É certo que nas grandes regiões metropolitanas, como é o caso de Campinas, a Pesquisa Origem e Destino fornece dados mais precisos e detalhados a respeito das condições de mobilidade da população. Porém, o Censo, dada a abrangência nacional, permite que a análise realizada nesta pesquisa seja replicada e, claro, aperfeiçoada, em outros recortes geográficos. 


\section{Referências}

AIDAR, T. A face perversa da cidade: configuração sócio-espacial das mortes violentas em Campinas nos anos 90. Campinas: Nepo/Unicamp, 2003 (Série Textos Nepo, 44). Disponível em: 〈http://www.nepo.unicamp.br/textos/publicacoes/textos_nepo/textos_nepo_44.pdf〉. Acesso em: 20 fev. 2013.

ANDRADE, S. M.; SOARES, D. A.; BRAGA, G. P.; MOREIRA, J. H.; BOTELHO, F. M. N. Comportamentos de risco para acidentes de trânsito: um inquérito entre estudantes de medicina na região sul do Brasil. Rev. Assoc. Med. Bras., v. 49, n. 4, p. 439-44, 2003.

BASTOS, Y.G.L.; ANDRADE, S.M.; SOARES, D.A. Características dos acidentes de trânsito e das vítimas atendidas em serviço pré-hospitalar em cidade do Sul do Brasil, 1997/2000. Cad. Saúde Pública, v. 21, n.3, p. 815-822, maio-jun. 2005.

BERTHO, A. C. S. Mobilidade cotidiana e acidentes de trânsito em Campinas-SP. Tese (Doutorado em Demografia) - Instituto de Filosofia e Ciências Humanas, Universidade Estadual de Campinas, Campinas, 2014.

Vulnerabilidade social e os acidentes de trânsito em Campinas-SP. Dissertação (Mestrado em Demografia) - Instituto de Filosofia e Ciências Humanas, Universidade Estadual de Campinas, Campinas, 2010.

CARDOSO, G.; GOLDNER, L. G. Desenvolvimento e aplicação de modelos para previsão de acidentes de trânsito. Transportes, v. XV, p. 43-51, dezembro 2007.

CHANDRAN, A.; KAHN, G.; SOUSA, T.; PECHANSKY, F.; BISHAI, D. M.; HYDER, A. A. Impact of road traffic deaths on expected years of life lost and reduction in life expectancy in Brazil. Demography, n. 50, p. 229-236, 2013.

DA MATTA, R.; VASCONCELLOS, J. G. M.; PANDOLFI, R. Fé em Deus e pé na tábua: ou como e por que o trânsito enlouquece no Brasil. Rio de Janeiro: Rocco, 2010.

EMDEC/SETRANSP. Malha de logradouros do Município de Campinas. Campinas, 2014.

Acidentes de trânsito em Campinas - 2009. Campinas, 2010. Disponível em: 〈http:// www.emdec.com.br/eficiente_old/repositorio/EMDEC_documentos/1799.pdf . Acesso em: 10 set. 2014.

GLOBAL ROAD SAFETY PARTNERSHIP. Speed management: a road safety manual for decision-makers and practitioners. Geneva. Disponivel em: «http://whqlibdoc.who.int/publications/2008/9782940395040_ eng.pdf>. Acesso em: 18 mai. 2014.

IBGE - Instituto Brasileiro de Geografia e Estatística. Censo Demográfico 2010. Microdados da amostra. Disponivel em: 〈http://censo2010.ibge.gov.br/resultados〉. Acesso em: 23 nov. 2012.

Metodologia do Censo Demográfico 2010. Rio de Janeiro, 2013 (Série Relatórios Metodológicos, v. 41). Disponível em: 〈ftp://ftp.ibge.gov.br/Censos/Censo_Demografico_2010/ metodologia/metodologia_censo_dem_2010.pdf〉.

JACOBS, G. D.; SAYER, I. Road accidents in developing countries. Accident Analysis and Prevention, v. 15, n. 5, p. 337-353, 1983.

LAURENTI, R.; GUERRA, M. A. T.; BASEOTTO, R. A.; KLINCERVICIUS, M. T. Alguns aspectos epidemiológicos da mortalidade por acidentes de trânsito de veículo a motor na cidade de São Paulo, Brasil. Rev. Saúde Públ., v. 6, n. 4, p. 329-41, 1972.

MAIA, P. B.; AIDAR, T. Mortes no trânsito urbano em São Paulo: relação entre residência das vítimas e local de ocorrência dos acidentes. São Paulo em Perspectiva, v. 21, n. 1, p. 46-59, jan./jun. 2007. 
MAIA, P. B. Mortalidade por acidentes de trânsito no município de São Paulo: uma análise intraurbana. 177 f. Tese (Doutorado em Demografia) - Departamento de Demografia, Instituto de Filosofia e Ciências Humanas, Universidade Estadual de Campinas, Campinas, 2009.

MELLO-JORGE, M. H. P. Mortalidade por causas violentas no município de São Paulo, Brasil. Rev. Saúde Públ., v. 14, p. 343-57, 1980.

MIRALLES-GUASCH, C. Ciudad y transporte: el binomio imperfecto. 1a. ed. Barcelona: Editorial Ariel, 2002.

SCALASSARA, M. B.; SOUZA, R. K. T.; SOARES, D. F. P. P. Características da mortalidade por acidentes de trânsito em localidade da região Sul do Brasil. Rev. Saúde Pública, v. 32, n. 2, p. 125-132, abr. 1998.

SOARES, D. F. P. P. Acidentes de trânsito em Maringá-PR: análise do perfil epidemiológico e dos fatores de risco de internação e de óbito. 2003. 220f. Tese (Doutorado em Ciências Médicas) Faculdade de Ciências Médicas, Universidade Estadual de Campinas, Campinas, 2003.

STM - Secretaria dos Transportes Metropolitanos. Pesquisa de Origem e Destino Domiciliar e Pesquisa de Linha de Contorno na Região Metropolitana de Campinas (Relatório). Campinas: Oficina Engenheiros Consultores Associados, 2012.

SOUZA, V. R.; CAVENAGHI, S.; ALVES, J. E. D; MAGALHÃES, M. M. Análise espacial dos acidentes de trânsito com vítimas fatais: comparação entre o local de residência e de ocorrência do acidente no Rio de Janeiro. R. Bras. Est. Pop., v. 25, n. 2, p. 353-364, jul./dez. 2008.

SOUZA, V. R. Análise especial dos acidentes de trânsito com vítimas fatais na cidade do Rio de Janeiro em 2003. 2007. 102f. Dissertação (Mestrado em Estudos Populacionais e Pesquisas Sociais) - Escola Nacional de Ciências Estatísticas, Rio de Janeiro, 2007. Disponível em: 〈www. ence.ibge.gov.br/images/ence/doc/mestrado/dissertacoes/2007/dissertaca02007_vanessa_ dos_reis_de_souza.pdf $>$. Acesso em: 3 ago. 2015.

WHO - World Health Organization. Global plan for the Decade of Action for Road Safety 20112010. Disponível em: 〈http://www.who.int/roadsafety/decade_of_action/plan/plan_english. pdf?ua=1〉. Acesso em: 10 fev. 2014.

Global status report on road safety 2013. Geneva, 2013. Disponível em: 〈http://www. who.int/violence_injury_prevention/road_safety_status/2013/en/>. Acesso em: 10 fev. 2014.

\section{Sobre as autoras}

Ana Carolina Soares Bertho é doutora em Demografia pela Universidade Estadual de Campinas - Unicamp. Pesquisadora e professora da Escola Nacional de Ciências Estatísticas - Ence/ IBGE e professora colaboradora no curso de mestrado do Programa de Pós-graduação em População, Território e Estatísticas Públicas da Ence/IBGE.

Tirza Aidar é doutora em Demografia pela Universidade Estadual de Campinas - Unicamp. Pesquisadora no Núcleo de Estudos de População “Elza Berquó” - Nepo/Unicamp e professora no Programa de Pós-graduação em Demografia no Instituto de Filosofia e Ciências Humanas IFCH/Unicamp.

\section{Endereço para correspondência}

\section{Ana Carolina Soares Bertho}

R. André Cavalcanti, 106, Bairro de Fátima

20231-050 - Rio de Janeiro-RJ, Brasil 


\author{
Tirza Aidar \\ Av. Albert Einstein, 1.300, Cidade Universitária \\ 13083-852 - Campinas-SP, Brasil \\ Caixa postal: 6166
}

\begin{abstract}
Everyday mobility and victimization rates from traffic accidents: what can be seen from demographic censuses data?
\end{abstract}

This paper assesses how the exposure to traffic accident risk can be potentiated by the conditions of everyday mobility of individuals. In the analysis, data from the Accidents Registry of fatal and non-fatal accidents in Campinas (São Paulo) in 2009 and the 2010 Demographic Census were used. The victims' places of residence were geocoded, allowing the calculation of victimization rates by area of consideration, which, in turn, were correlated to socioeconomic and mobility information. Although the findings do not permit conclusions at individual level, it was found that areas with a higher proportion of low-income population had lower accident rates. On the other hand, it was observed a negative correlation between areas with a higher proportion of high-income population and victimization rates of motorcyclists. The results show a positive correlation between the proportion of people with household income per capita that is 1 to less than 2 and 2 to less than 3 times the minimum wage and rates of victimization. This is true as well for people ages 25 to 39 who completed high school. The results suggest an unequal use of public roads, where those who can afford moving do it safely and those who cannot afford moving do it less frequently, and, when the latter have minimal economic conditions, move less safely.K

Keywords: Traffic accidents. Everyday mobility. Health inequalities.

\title{
Resumen
}

Movilidad cotidiana y tasas de victimización por accidentes de tránsito: ¿qué se puede entrever a partir de los datos censales?

En este estudio se analiza la forma en que la exposición al riesgo de accidentes de tránsito puede ser potenciada por las condiciones de la movilidad cotidiana de los individuos. Para este propósito se utilizaron los datos del Boletín de ocurrencia de accidentes fatales y no fatales en Campinas (São Paulo) en 2009 y del censo demográfico de 2010. Los lugares de residencia de las víctimas fueron georreferenciados, lo que permitió el cálculo de los índices de victimización por accidentes por área de ponderación, los que a su vez se relacionaron con información socioeconómica y de movilidad. Aunque las conclusiones no pueden inferirse para el nivel individual, se encontró que en las zonas con una mayor proporción de personas con bajos ingresos se registraban menores tasas de accidentes. Por otra parte, se observó una correlación negativa entre las áreas con mayor proporción de personas con altos ingresos y las tasas de victimización de motociclistas. Los resultados muestran una correlación positiva entre las áreas con mayor proporción de personas con ingreso familiar per cápita de 1 a 2 y de 2 a 3 salarios mínimos y las tasas de victimización por accidentes, así como entre aquellas con mayor proporción de personas de 25 a 39 años con enseñanza media completa. Estos resultados refuerzan la idea de una posible utilización desigual de la vía pública, en la que aquellos que 
pueden se desplazan de forma segura, los que no pueden se desplazan poco, y cuando cuentan con las condiciones económicas mínimas, lo hacen en condiciones de seguridad escasas.

Palabras clave: Accidentes de tránsito. Movilidad cotidiana. Desigualdades en salud.

\section{Apêndice}

TABELA 1

Estatísticas descritivas das variáveis incluídas no estudo, segundo as 36 áreas de ponderação Município de Campinas - 2010

\begin{tabular}{|c|c|c|c|c|c|c|c|}
\hline Variáveis e categorias & Mínimo & Máximo & Mediana & Média & $\begin{array}{l}\text { Desvio- } \\
\text { padrão }\end{array}$ & $\begin{array}{l}\text { Skewness } \\
\text { (a) }\end{array}$ & $\begin{array}{l}\text { Kurtosis } \\
\text { (b) }\end{array}$ \\
\hline \multicolumn{8}{|l|}{$\begin{array}{l}\text { Taxa de vitimização devido } \\
\text { a acidentes de trânsito por } \\
100 \text { mil hab. }\end{array}$} \\
\hline Total & 50,0 & 562,6 & 327,2 & 330,4 & 110,1 & $-0,10$ & 0,33 \\
\hline Pedestres & 0,0 & 97,7 & 44,4 & 47,4 & 20,5 & 0,26 & 0,42 \\
\hline Motociclistas de 15 a 34 anos & 72,8 & 916,1 & 482,0 & 465,5 & 202,2 & 0,16 & $-0,46$ \\
\hline \multicolumn{8}{|l|}{$\begin{array}{l}\text { População (\%) residente em } \\
\text { domicílios com carro ou moto }\end{array}$} \\
\hline Nenhum & 5,6 & 47,2 & 22,7 & 23,3 & 12,4 & 0,47 & $-0,87$ \\
\hline Somente moto & 0,0 & 1,1 & 0,4 & 0,4 & 0,3 & 0,61 & $-0,32$ \\
\hline Somente carro & 34,0 & 83,3 & 58,8 & 58,8 & 12,2 & 0,01 & $-0,66$ \\
\hline Ambos & 4,2 & 23,8 & 13,1 & 13,6 & 4,5 & 0,12 & $-0,39$ \\
\hline \multicolumn{8}{|l|}{$\begin{array}{l}\text { População (\%) segundo tempo } \\
\text { do deslocamento casa-trabalho }\end{array}$} \\
\hline Até 5 minutos & 2,0 & 13,6 & 5,7 & 6,5 & 3,0 & 0,76 & $-0,13$ \\
\hline De 6 a 30 min. & 14,5 & 74,5 & 52,1 & 46,9 & 14,6 & $-0,39$ & $-0,73$ \\
\hline Mais de 30 a 60 min. & 15,0 & 49,8 & 31,6 & 33,4 & 9,7 & $-0,07$ & $-1,25$ \\
\hline Mais de 60 min. & 4,6 & 38,7 & 9,4 & 13,0 & 8,8 & 1,67 & 2,25 \\
\hline \multicolumn{8}{|l|}{$\begin{array}{l}\text { Escolaridade da população } \\
\text { de } 25 \text { a } 39 \text { anos (\%) }\end{array}$} \\
\hline $\begin{array}{l}\text { Nenhuma ou fundamental } \\
\text { incompleto }\end{array}$ & 2,7 & 52,1 & 20,8 & 21,2 & 11,9 & 0,61 & $-0,04$ \\
\hline Fundamental completo & 1,6 & 28,9 & 17,0 & 16,0 & 6,9 & $-0,14$ & $-0,79$ \\
\hline Ensino médio completo & 17,3 & 51,1 & 37,5 & 35,7 & 7,9 & $-0,43$ & $-0,17$ \\
\hline Superior & 1,6 & 78,2 & 21,3 & 26,1 & 21,0 & 0,67 & $-0,51$ \\
\hline \multicolumn{8}{|l|}{$\begin{array}{l}\text { População (\%) segundo renda } \\
\text { domiciliar per capita em } \\
\text { salários mínimos }\end{array}$} \\
\hline Menos de 1 SM & 5,5 & 71,5 & 34,8 & 36,5 & 17,7 & 0,30 & $-1,06$ \\
\hline De 1 a menos de 2 SM & 11,3 & 40,0 & 29,2 & 27,9 & 7,1 & $-0,60$ & 0,15 \\
\hline De 2 a menos de $3 \mathrm{SM}$ & 3,8 & 21,2 & 12,7 & 11,9 & 4,1 & 0,05 & $-0,53$ \\
\hline A partir de 3 SM & 1,3 & 74,6 & 18,0 & 23,5 & 19,3 & 0,66 & $-0,42$ \\
\hline $\begin{array}{l}\text { Média do rendimento domiciliar } \\
\text { per capita }\end{array}$ & 427,06 & $4.780,94$ & $1.085,95$ & $1.390,04$ & 938,52 & 1,55 & 3,36 \\
\hline $\begin{array}{l}\text { Mediana do rendimento domiciliar } \\
\text { per capita }\end{array}$ & 334,00 & $3.500,00$ & 704,38 & 921,70 & 616,77 & 2,43 & 8,02 \\
\hline
\end{tabular}

Fonte: IBGE. Censo Demográfico 2010. Emdec/Setransp (2010).

Nota: Não há evidência estatística para rejeitar as hipóteses: simetria da distribuição; e adequação de concentração em torno da média. 


\section{GRÁFICO 1}

Taxas de vitimização devido a acidentes de trânsito por média da renda domiciliar per capita, segundo tipo de acidente para áreas de ponderação

Município de Campinas - 2010

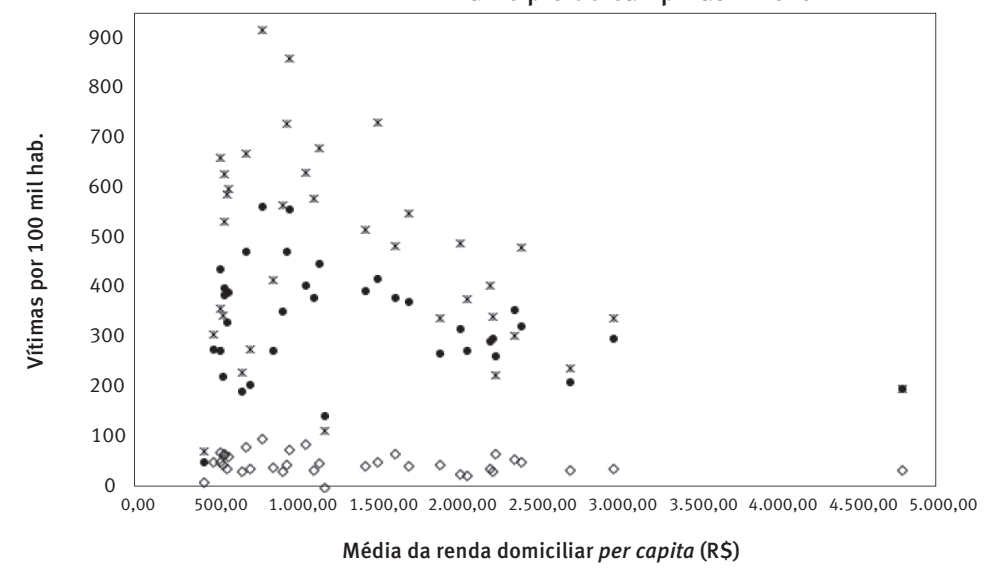

- Total

- Pedestres

* Motociclistas

Fonte: IBGE. Censo Demográfico 2010. Emdec/Setransp (2010).

GRÁFICO 2

Taxas de vitimização devido a acidentes de trânsito por percentual de população com renda domiciliar per capita de 1 a menos de 2 salários mínimos, segundo tipo de acidente para áreas de ponderação Município de Campinas - 2010

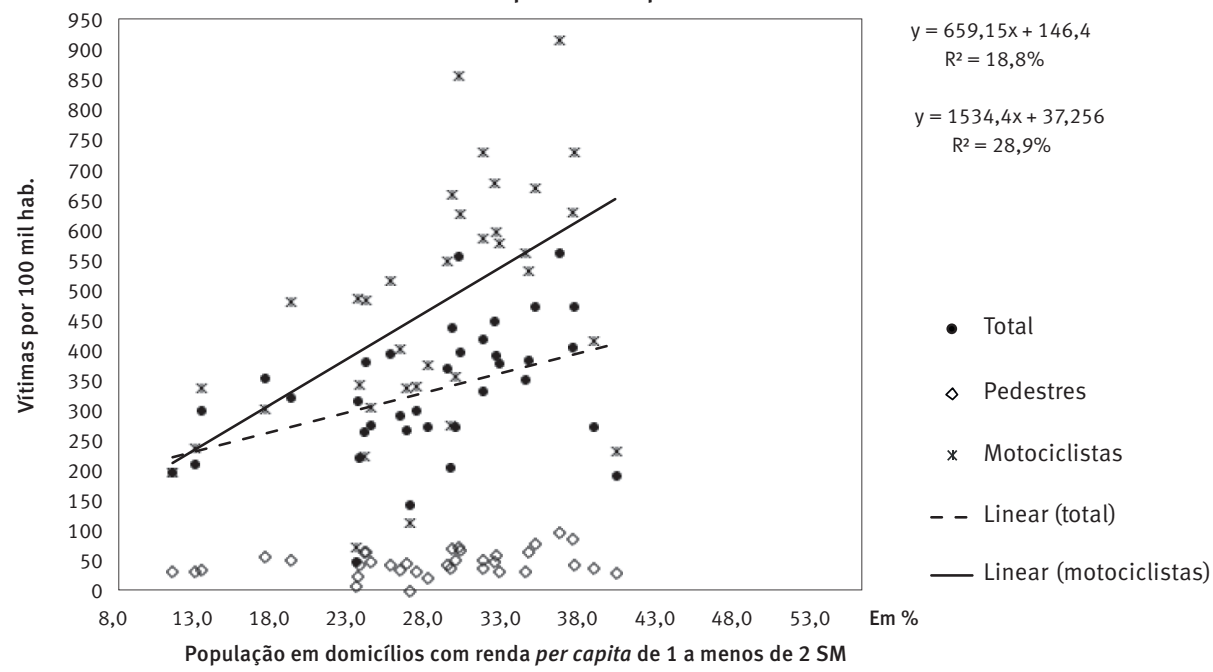

Fonte: IBGE. Censo Demográfico 2010. Emdec/Setransp (2010). 


\section{GRÁFICO 3}

Taxas de vitimização devido a acidentes de trânsito por percentual de população de 25 a 39 anos com ensino médio completo, segundo tipo de acidente para áreas de ponderação Município de Campinas - 2010

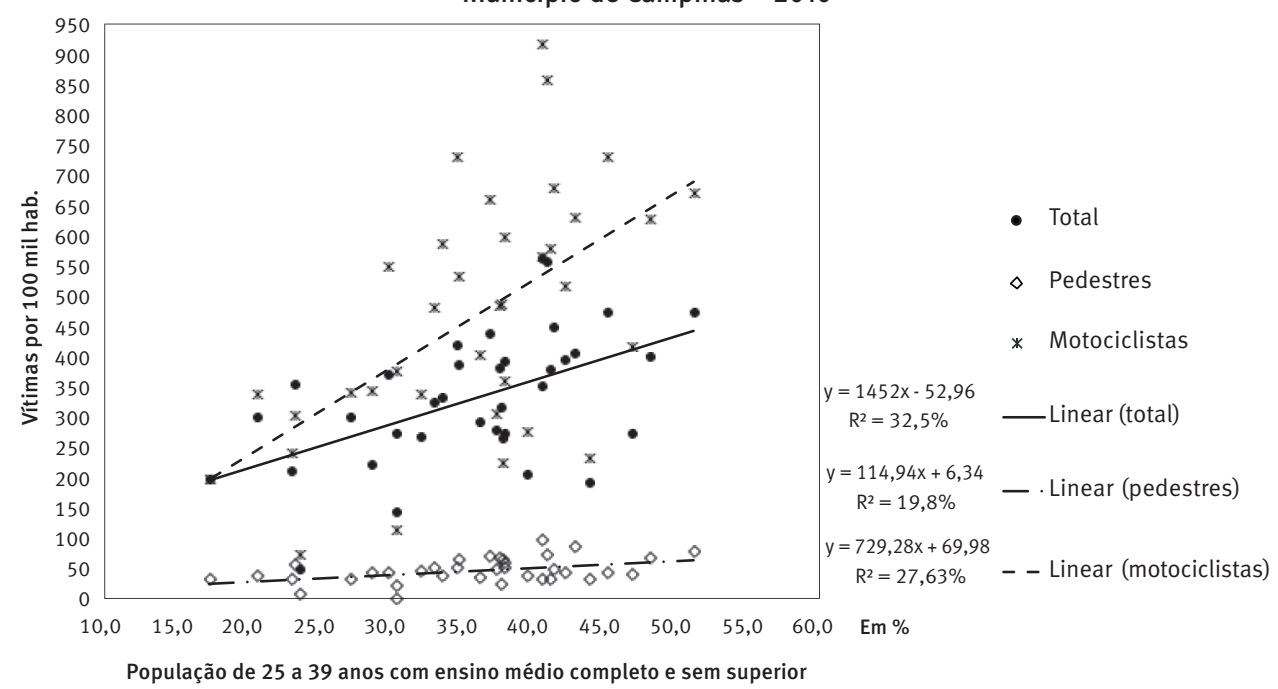

Fonte: IBGE. Censo Demográfico 2010. Emdec/Setransp (2010).

GRÁFICO 4

Taxas de vitimização devido a acidentes com motocicletas por percentual da população com tempo de deslocamento casa-trabalho inferior a seis minutos para áreas de ponderação

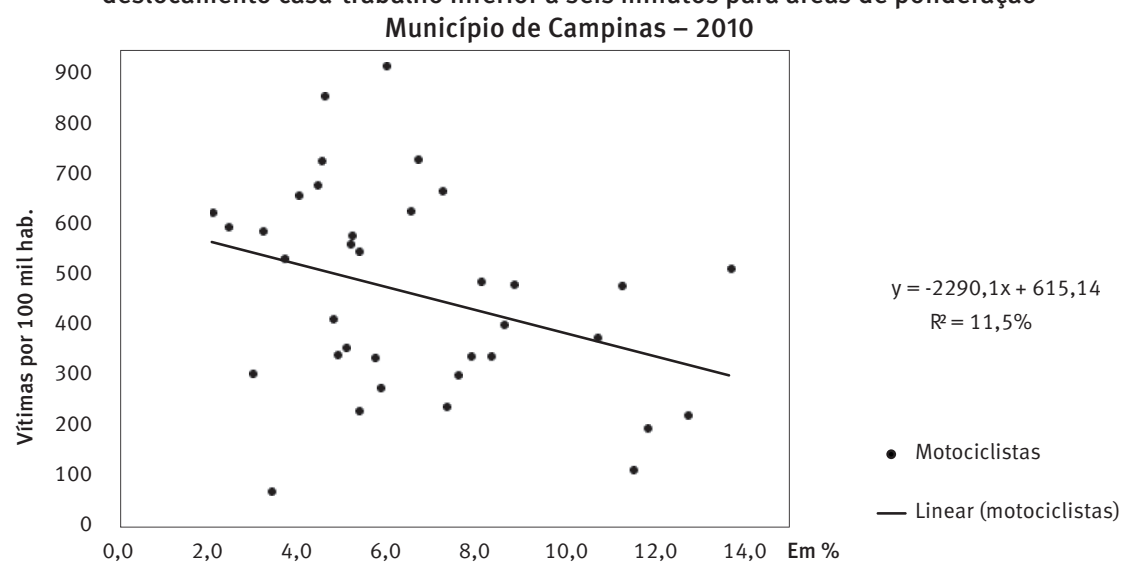

População com tempo de deslocamento casa-trabalho inferior a seis minutos

Fonte: IBGE. Censo Demográfico 2010. Emdec/Setransp (2010).

Recebido para publicação em 25/10/2014 Recomendado para publicação em 15/02/2015

Aceito para publicação em 02/08/2015 